\title{
Home Based Physical Exercise for Prevention and Management of COVID-19 Pandemic and for Its Associated Consequences
}

\author{
Getu Teferi \\ Department of Sports Science, Debremarkos University, Debremarkos, Ethiopia \\ Email address: \\ teferigetu36@gmail.com \\ To cite this article: \\ Getu Teferi. Home Based Physical Exercise for Prevention and Management of COVID-19 Pandemic and for Its Associated Consequences. \\ European Journal of Preventive Medicine. Vol. 8, No. 6, 2020, pp. 97-105. doi: 10.11648/j.ejpm.20200806.11
}

Received: August 26, 2020; Accepted: September 14, 2020; Published: November 23, 2020

\begin{abstract}
Background: Corona viruses are sort of viruses that are phenotypically and genotypically diverse. COVID-19 pandemic reported the first time on December 2019 in Wuhan, China. Mental and physical well-being are negatively affected by sedentary habits and positively affected by active lifestyle. Method: The research method of this article is a systematic review and Based on titles and abstracts, reference the articles were screened for eligibility, i.e. included publications regarding the effect of physical activity on Covid-19. search strategy by used terms in relation with physical activity and Covid-19. Results: The COVID-19 pandemic has forced many people around the world to stay at home and self-isolate for a long period of time. These leads to psychological outcomes such as depression, post-traumatic stress symptoms, panic, confusion, anger, fear, and substance misuse and develops Sedentary Death Syndrome and reduce individuals' functional ability. Conclusion: Increased physical activity levels and fitness help alleviate or relieve Covid-19 associated health problems such as depression, anxiety and stress (mental health) and at this time if an individual follows a physically active lifestyle or participate regularly in home based physical activity, it has been found to be an effective way of improving fitness and overall health of individual. The effect of regular home based exercise training has a significant positive effect on overall health of individuals. Mental and physical well-being are negatively affected by sedentary habits and positively affected by active lifestyle.
\end{abstract}

Keywords: Home-based Physical Activity, COVID-19, Physical Inactivity and Pandemic

\section{Introduction}

Corona viruses are sort of viruses that are phenotypically and genotypically diverse. COVID-19 pandemic reported the first time on December 2019 in Wuhan, China. As of 17 March 2020, the widespread human-to-human transmission now had resulted over 21 million people infected. Because the COVID-19 pandemic continues to develop in most countries and various prevention strategies are introduced by the gov't of just about all countries, including the closing of faculties and universities, and bans on travel, cultural and sporting events, and social gatherings [1]. People are ordered or advised to remain reception, and a number of other countries have requested all returning travelers to self-isolate for a fourthnight. Of these actions are considered as an effective measure for preventing the virus spreading and for managing those that do contract the virus. But these actions will negatively affect people's physical activity habits, with longer spent by sitting and watching screens and a subsequent impact on physical health, well-being, sleeping patterns and quality of life. The beneficial effects of normal workout on many health outcomes are well established. Different research has demonstrated specific benefits like improved physical and physiological health parameters and positive health outcomes in areas of psychological state and wellbeing [2-5]. For these reasons, implementing home based physical activity programme during the amount of the pandemic will reduce the negative physiological and psychological state impact of sedentary behaviors. According to the regulations recently set by the Ethiopian government, for instance, it's mandated that each one peoples must remain reception unless required to maneuver for valid reasons, like work, health or for other 
unavoidable issues like assisting those that are sick or disabled, or purchasing groceries and medications. All sporting activities and competitions are cancelled. However, one important exception has been made to permit people to practice sports and outdoor physical activity, as long as an interpersonal distance of a minimum of $1 \mathrm{~m}$ might be maintained. "Sedentary Death Syndrome" If, in fact, quarantine experience increases can cause psychological problems like depression, post-traumatic stress symptoms, panic, confusion, anger, fear, and substance misuse [6], it also can give the thanks to several patho-physiological mechanisms arising from inactivity. Physical inactivity are often defined because the range of situations that, thanks to impossibility of movement (paralysis) or personal habit (long sitting hours), produce decreased energy expenditure toward basal level [7]. It's important to understand that pathologies or worsening of medical conditions caused by inactivity often show their symptoms and manifestations over the future, and are usually pre-clinically silent. it's estimated that physical inactivity is responsible, worldwide, for between $6 \%$ and $10 \%$ of non-communicable disease, including, among others, paralysis, strokes, heart diseases, cancers, diabetes, chronic renal disorder, osteoarthritis, osteoporosis, Alzheimer's disease, and Parkinson's disease [8]. Physical inactivity also increases the loss of functional abilities with aging, resulting in decreases in anticipation, with impacts potentially as large as renowned risk factors like smoking and obesity. The term "sedentary death syndrome" was first wont to give attention to the present alarming problem, warning about the risks related to the imbalance between calorie intake and output, which may cause hyperinsulinemia and thus adiposity. Overweight, or worse, obesity, are largely related to an increased risk of cardiovascular problems, osteoporosis, osteoarthritis muscle wasting, and overall physical and mental distress [9-11].

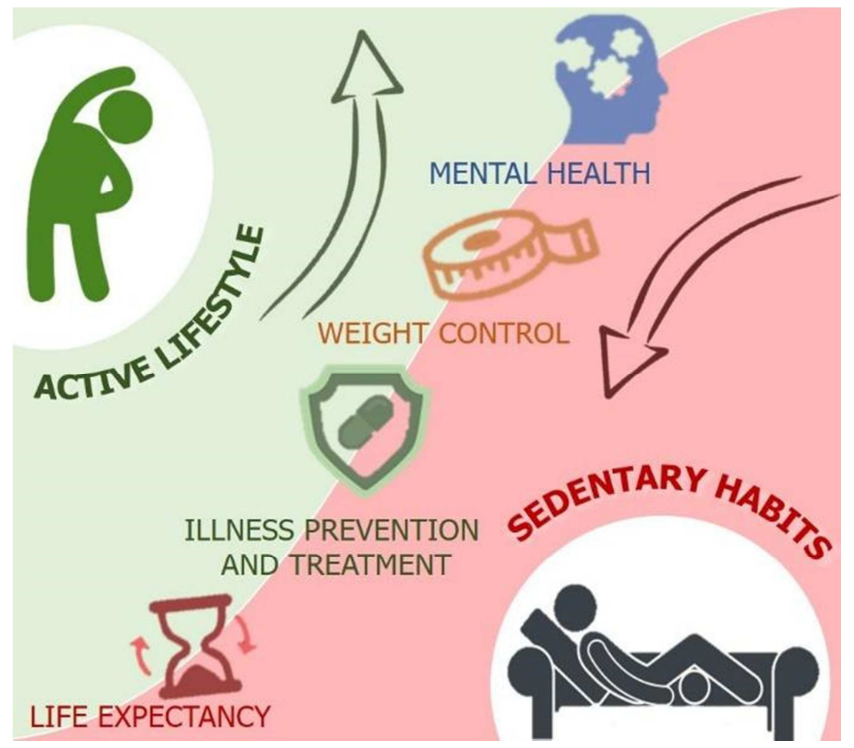

Figure 1. Mental and physical well-being are negatively affected by sedentary habits and positively affected by active lifestyle.

In this context, physical activity doesn't only represent a crucial a part of disease prevention but also drugs for inactivity-associated disorders. Physical activity represents a non-pharmacological approach for promoting general health [12].

\section{Objectives of the Study}

1. To describe the most effectivehome based physical activity during Covid -19 pandemic.

2. To show the effect of physical activity on Covid-19 associated consequences.

\section{Methods}

The method of this research is a systematic review research. The review of related literature seeking strategy were used basic terms in relation with physical activity and Covid-19: such as home based physical activity and Covid 19, regular exercise and Covid 19, the effect of physical activity on Covid 19 associated health problems, most effective exercise for Covid 19, physical activity and psychological problems. Search of scientific evidence was conducted in the following bibliographic databases: online research databases, web of knowledge, and science direct, sport discus, Google scholar, the references of all saved articles and organizations were reviewed for relevant citations.

\subsection{Inclusion Criteria}

All publications or articles focused in which there were the terms in relation with the effect of physical activity on Covid-19. Studies based on written in English, between the year 2000to recent were also included.

\subsection{Exclusion Criteria}

The criteria such as articles written in other languages rather than English and published before the year 2000.

\subsection{Screening of Articles for Eligibility}

Based on titles and abstracts, reference the articles were screened for eligibility, i.e. included publications regarding the effect of physical activity on Covid-19. All included articles were read critically and significant information was extracted. From the selected publications, organizations and articles the following data such as year of study, characteristic of analysis, evaluation and resultswere extracted. The electronic databases and the manual search of reference lists identified 125 articles. On the basis of title and abstract, we excluded 32 studies that did not meet inclusion criteria. All information was obtained directly from the articles.

\section{Recommendations on Physical Activity}

The World Health Organization (WHO) has suggested clear guidelines on the minimal amount of physical activity necessary to take care of health. For instance, it recommend that adults aged between 18 and 64 years, the age bracket 
most suffering from COVID-19 consistent with recent statistics (i.e. accounting for over $70 \%$ of all severe cases), should engage in weekly training of a minimum of $150 \mathrm{~min}$ of moderate-intensity physical activity or $75 \mathrm{~min}$ of vigorousintensity physical activity, or a corresponding combination of moderate- and vigorous-intensity activity [13]. Current evidences also support to the benefits of normal physical activity on survival [14-16]. Physical Activity and psychological state Obesity and overweight rates among all groups in society, no matter age, sex, race, socioeconomic status, educational level, or geographical area have noticeably increased within the last twenty years [17]. Obesity and overweight aren't just a private matter; it's also public health epidemics that affects education achievement outcomes, economic productivity, state budgets and successively affect students' academic achievement [18, 19]. Additionally to disease prevention, studies suggest that physical activity directly benefits cognition and academic achievement. In one study, during which children jogged for thirty minutes two to fourfold per week, researchers measured a rise in activity within the prefrontal cortex, suggesting greater cognitive function. However, the cognitive gains were only sustained while children maintained the jogging regimen [20-21]. If a private follows a physically active lifestyle, it's been found to be an efficient way of improving fitness and overall health [22]. Conversely, the absence of a physically active lifestyle can adversely affect health and well-being, increasing the danger of somatic health problems like cardiovascular diseases, hypertension, DM, osteoporosis, and a few sorts of cancer [23]. Additionally, regular PA is understood to possess a positive impact on psychological state [24]. variety of meta-analyses of intervention studies of the effect of exercise training have revealed that exercise may have a big moderate to high antidepressive effect [25-27]. In other way if students have poor fitness different problems are appearing additionally to academic achievement problems like apnea, which has been linked to problems with learning and memory, liver problems, orthopedic problems and asthma. If there's apnea problem in children, it can to impair a child's ability to concentrate and stay alert during the day, which could have a negative impact on academic performance [28] also reported, supported their study results, being physically fit reduces the danger of disorder, carcinoma, diabetes, dying prematurely, and obesity. Increased physical activity levels and fitness can improve bone and musculoskeletal function and help alleviate or relieve depression, anxiety and stress (mental health)[28]. Generally the previous research findings from large-scale observational studies indicated that participation in physical activity features a small to moderate effect in prevention and management of the danger of depression and anxiety which successively have effect on academic achievement and psychological state [29-37]. Reductions in physical activity can also affect one's psychological state, which can be experienced as unpleasant emotions like sadness, anger, frustration and /or irritation. During a review on psychological impact of quarantine recently performed by
Brooks et al., the authors stated that experiencing disease outbreaks can trigger symptoms of post-traumatic stress, depression and /or confusion among others [38-40]. During quarantine, staying active and maintaining a workout routine is going to be essential for mental and physical health. Fortunately, a good range of exercises, like video- or appguided equipment-free aerobics or strength training, are often performed reception and will be encouraged. We hence encourage national, federal and region al governments round the world to incorporate clear exceptions for physical activity in nationwide lockdowns. These should also leave safe performance of outside physical activities (e.g. walking, running or other individual sports, where an adequate interpersonal distance are often maintained). consistent with [41] are often concluded that workout are often beneficial for the defenses of the entire body and should be counted among preventative measures against the results of tract virus infection, that, on the opposite hand, sedentary habits might be related to increased risk of predisposition to infections.

\section{Impact of COVID-19 and Physical Inactivity on the Immune System}

SARS-CoV-2 mayresults coronavirus disease (COVID19) shows the major symptoms of ever, dry cough, myalgia, and fatigue $[42,43]$. Currently, there are neither vaccines nor clinically proven effective medicines. Convalescent plasma and anti-viral drugs (e.g., Remdesivir) have shown some hopes in treating COVID-19 patients [44], but their widespread use await statistical rigor. Currently the best and only measures to reduce the spread, morbidity and mortality are social distancing and hygiene. As this virus strain is novel to the human immune system, we are dependent on aspects of our innate resistance to deal with the first infection. Like other viral infections, if we resist the infection, over the course of weeks we can develop antibody and cell-mediated immune responses specific to the virus. In most instances, this exposure-related 'training' of our immune systems offers us long-lasting protection from re-infection or, if we are re-infected, disease symptoms are much milder [45].

Physical activity affects the immune system and its antiviral defenses positively [43, 46, 47]. Animal experiments administering influenza and herpes simplex viruses 1 (HSV-1) in the respiratory tract, have revealed that moderate exercise, performed before (i.e. training) or after infection (for a few days before symptom onset), improves morbidity and mortality to theinfection [48-50]. In other way, preclinical studies have also shown that intense exercise leads to poorer outcomes in response to respiratory viral infections [51, 52]. Follow-up research findings have concluded on some understanding of the mechanisms responsible for these observations [53-56].

The current epidemiological study has showed that intense, prolonged exercise was correlated with an increase in upper respiratory tract infections [57]. This work leads to the 
concept of the inverted $\mathrm{J}$ theory, where moderate intensity of exercise reduces, and prolonged, high intensity exercise [58] increases susceptibility to infection. Many research findings have supported the theory with respect to individual immune parameters including those specific to viral defense. For example, salivary lactoferrin and its secretion rate increased for up to 2 hours after moderate intensity of physical exercise [59]. Mucosal lactoferrin is very important because it can protect DNA and RNA viruses form infecting cells by binding and blocking host receptors. In other way, low levels or secretion rates of salivary immunoglobulin A, which can bind to viruses and inactivate them, has been shown to be associated with upper respiratory tract infection in some individuals who undergoing intense physical exercise training $[44,60]$. In addition, because physical exercise leads to profound movement of leukocytes in blood and tissues [61-63], many researchers conclude that being physically active increases immune surveillance against infectious pathogens including viruses.

\section{COVID-19, Physical Activity, and the Respiratory System}

While the clinical research of the COVID-19 pandemic continues to be investigated, many OVID-19 patients develop respiratory failure and require mechanical ventilation (MV) to maintain adequate pulmonary gas exchange. In this regard, a recent report reveals that $\sim 54 \%$ of patients hospitalized thanks to COVID-19 experience respiratory failure and $>30 \%$ require MV [44, 45]. Although MV is usually a life-saving intervention, an unwanted consequence of prolonged $\mathrm{MV}$ is that the rapid development of respiratory muscle weakness thanks to diaphragm muscle atrophy and contractile dysfunction (collectively termed ventilator-induced diaphragm dysfunction, VIDD). VIDD is clinically significant because diaphragmatic weakness may be a major contributor to the lack to wean patients from the ventilator [46]. Many COVID19 patients often require prolonged time on the ventilator that increases the danger of weaning problems. Patients who experience difficult weaning suffer higher morbidity and mortality than patients weaned quickly on their first attempts to break away the ventilator $[49,64]$ and unfortunately, many COVID-19 patients succumb to ICU-related complications (e.g., sepsis). As long as respiratory muscle weakness may be a primary risk factor for failure to wean from the ventilator, developing strategies to guard the diaphragm against MVinduced weakness has become a priority in critical care medicine. Interestingly, different studies have showed positive impact of endurance exercise training on the systemarespiratorium has led the way. Although many organ systems adapt in response to endurance exercise training, the structural and functional properties of the lung and airways aren't altered thanks to exercise [65] training. Specifically, endurance exercise training promotes numerous biochemical alterations in diaphragm muscle leading to a phenotype that's protected against several challenges including prolonged $\mathrm{MV}$
[66]. Indeed, as few as 10 consecutive days of endurance exercise training leads to significant protection against VIDD [67-69]. Therefore, it's predicted that endurance trained individuals that develop COVID-19 and need ventilator support will enjoy the exercise-induced preconditioning of the diaphragm.

\section{PA and Exercise Programming During a Pandemic}

The effect of regular physical exercise on noncommunicableand also have positive impact on the immune system and modern lifestyle behaviors promote physical inactivity which leads peoples become sedentary [70-73]. These poor lifestyle behaviors are intensified by social distancing and self-imposed or authorities mandated quarantine measures intended to reduce COVID-19 spread. These circumstances pose significant challenges for remaining physically active. during times of isolation, all socioeconomic groups, ethnicities, and ages should maintain healthiness by following the PA recommendations of 150 minutes of moderate-intensity or 75 minutes of vigorous-intensity PA per week, or a mixture of both. Muscle-strengthening activities [75] involving major muscle groups are recommended on two or more days per week. In children/adolescents the recommendations include at least 60 minutes per day of vigorous or [76] moderate intensity PA.

\section{Starting an Exercise Program Duringa Pandemic}

When starting physical exercise program while in the midst of pandemic, public health recommendations for social distancing and hygiene practices should be considered. Becoming physically active and reducing sedentary behavior is definitely accomplished by avoiding sitting for while periods, taking short movement or activity breaks, utilizing online exercise classes, and using mobile technologies like telephone applications and wearable sensors to encourage movement. A goal of any beginning PA or exercise program is to progressively work toward completing a minimum of one-half hour of moderate PA a day or a minimum of twenty minutes of vigorous PA every other day of the week. Ideally, strengthening-type activities are included in daily activities a minimum of twice every week [73]. Individuals have chronic diseases like cardiovascular or pulmonary disease should seek advice from health care providers regarding safe exercises [74-76]. Recommendations for youngsters and youth aged five to 17 years are the buildup of a minimum of hour of moderate - to vigorous-intensity daily PA. additionally, vigorous-intensity physical activities that strengthen muscle and bone are recommended a minimum of three [74] times per week. If engaged in regular workout and 
eager to further enhance cardiovascular and muscle fitness, suddenly beginning an intense aerobic and resistance exercise educational program or performing unaccustomed highly intense prolonged exercise isn't prudent, because such PA or exercise training can cause reduced immune function.

\section{Recommended Home-based and Individualized Physical Activity}

There is likely to be very limited opportunity to practice physical activity outside home during this pandemic period, with most of the people advised to remain reception to stop transmission of the virus. it's thus recommended that folks should stay active by exercising at their home. For this purpose promoting physical activity is extremely important, multiple exercise modes are often applied, including aerobics using stationary bikes or rowing ergo meters, weight strength training, dance-based exercise and active gaming. for youngsters and youth (5-17 yrs), WHO recommends $60 \mathrm{~min}$ of daily physical activity with moderate to vigorous aerobic intensity, with muscle and bone strengthening three days per week [77]. For adults and elderly ( $>17 \mathrm{yrs})$, recommend physical activity for $75 \mathrm{~min} / \mathrm{wk}$ with vigorous aerobics intensity or $150 \mathrm{~min} / \mathrm{wk}$ of moderate aerobic intensity, with muscle and bone strengthening two days per week [77]. The aerobics training types are described in Table 1 below for trained and untrained individuals, with the specific intensity associated with pulse, rating of perceived exertion (RPE) also as intensity with regard to the degree of breathlessness during exercise [78-80]. Dancing activities reception, audio-visual directed gymnastics and aerobics are often recommended for maintenance of cardiovascular, metabolic and musculoskeletal fitness and for reducing the severity of symptoms of depression and anxiety [81-85]. Dance-based workout involves the utilization of body movements which helps to enhance

Table 1. Exercise Intensity Types of home-based aerobic exercise training for various target groups [86].

\begin{tabular}{llllllll}
\hline \multirow{2}{*}{ Intensity } & \multicolumn{3}{l}{ Active/Trained } & \multicolumn{3}{l}{ Sedentary } & \multicolumn{3}{l}{ Patients/Elderly } & \multirow{2}{*}{ Intensity description/definition } \\
\cline { 2 - 6 } & \% HRmax & RPE (0-10) & \%HRmax & RPE (0-10) & \%HRmax & RPE (0-10) & \\
\hline $65(50-80)$ & $2(1-3)$ & $60(50-75)$ & $2(1-3)$ & $60(50-70)$ & $2(1-3)$ & $\begin{array}{l}\text { Easy, breath is moderate } \\
\text { Somewhat hard, Breath quickens, talking is } \\
\text { possible but not singing } \\
\text { Challenging, breath is deep and rapid, only few } \\
\text { words can be said without pausing for breath }\end{array}$ \\
\hline
\end{tabular}

Note: Heart rate in percentage of maximal heart rate (HRmax) and rating of perceived exertion (RPE) during aerobic training with low, moderate and high intensity exercise for trained/active [78] as well as sedentary individuals and patients/elderly [80]. The session RPE 0-10 scale relates to the following intensity anchors; 0: Rest, 2: Easy, 3: Moderate, 5: Hard, 7: Very Hard, 10: Maximal (Foster et al., 2001). Please note that the intensity categories are described as mean values as well as ranges. HRmax can be estimated as 220 minus age (Fox et al., 1971) or 208 minus 0.7 multiplied by age [87].

Strength training, simply stated, is any type of exercise that involves using the body as a means of resistance to perform work against gravity [88]. Examples of body weight exercises for the upper and lower body include push -ups, pull-ups, squats, lunges, box jumps and jump roping. The benefits of body weight training for musculoskeletal health and functional capacity are well supported by different scientific evidence $[89$, 90]. For example, it has been indicated that plyometric exercise as well as resistance exercise with slow movements can improve physical function in the elderly [90, 91]. Moreover, different research findings have shown that 10 weeks of weight training improved selected elements of body composition and components of physical fitness, including strength, flexibility and aerobic capacity, in sedentary $21-23$ yr-old women [92]. UNESCO has announced that about 861.7 million students are out of school because of COVID-19. It is likely that this pandemic will increase mental health problems in some children and adolescents. Thus, motivating physical exercise program can be effective strategies to keep young people active at home. Active lifestyle can to impact the health and fitness of young people.

\section{Conclusion}

Generally, home- basedregular physical exercise program can provide an opportunity for people to stay physically healthy by practicing simple movements with low-moderate to high intensity in the time of staying at home. The best way to overcome Covid -19 associated problemsis to substitute outdoor regular exercise program with homebased/individualized/ regular exercise program, such as bodyweight training and dance-based aerobic exercise, and if possible, aerobic high-intensity exercise using different machines, also with self paced protocols. These physical exercises can be combined with, but not substituted by, stretching and active gaming. The great importance of a healthy diet during this pandemic period also should give more attention. Generally, maintaining a regular physical activity raining, carefully in a park setting or safely at home, is a helpful strategy toreduce the consequences of this pandemic, both at the physical and mental level. The time spent at home could therefore be changed into by participating mostly in home based aerobic exercise to build a positive and mindful relationship with the long-term health benefits of exercising.

\section{Acknowledgements}

I would like to Mr. Awoke Tibebu for his editing and constructive comment for this review paper. 


\section{References}

[1] Parnell, D., Widdop, P., Bond, A., \& Wilson, R. (2020). COVID-19, networks and sport. Managing Sport and Leisure, https://doi.org/10.1080/23750472.2020.1750100.

[2] Pedersen, B. K., \& Saltin, B. (2015). Exercise as medicine evidence for prescribing exercise as therapy in 26 different chronic diseases. Scandinavian Journal of Medicine \& Science in Sports, 25 (S3), 1-72. https://doi.org/10.1111/sms. 12581.

[3] Powell, K. E., Paluch, A. E., \& Blair, S. N. (2011). Physical activity for health: What kind? How much? How intense? On top of what? Annual Review of Public Health, 32 (1), 349 365. https://doi.org/10.1146/annurev-publhealth-031210101151 .

[4] Chekroud, S. R., Gueorguieva, R., Zheutlin, A. B., Paulus, M., Krumholz, H. M., Krystal, J. H., \&Chekroud, A. M. (2018). Association between phys-ical exercise and mental health in 1.2 million indi-viduals in the USA between 2011 and 2015: A cross-sectional study. The Lancet Psychiatry, 5 (9), 739 746. https://doi.org/10.1016/S2215-0366(18)30227-X.

[5] Mathieu, R. A., Powell-Wiley, T. M., Ayers, C. R., McGuire, D. K., Khera, A., Das, S. R., \& Lakoski, S. G. (2012). Physical activity participation, health per-ceptions, and cardiovascular disease mortality in a multiethnic population: The Dallas heart study. American Heart Journal, 163 (6), 1037-1040. https://doi.org/10.1016/j.ahj.2012.03.005.

[6] Booth, F. W.; Roberts, C. K.; Thyfault, J. P.; Ruegsegger, G. N.; Toedebusch, R. G. Role of Inactivity in Chronic Diseases: Evolutionary Insight and Pathophysiological Mechanisms. Physiol. Rev. 2017, 97, 1351-1402. [CrossRef] [PubMed].

[7] Lee, I. M.; Shiroma, E. J.; Lobelo, F.; Puska, P.; Blair, S. N.; Katzmarzyk, P. T. E ect of physical inactivity on major noncommunicable diseases worldwide: An analysis of burden of disease and life expectancy. Lancet 2012, 380, 219-229. [CrossRef].

[8] Lees, S. J.; Booth, F. W. Sedentary death syndrome. Can. J. Appl. Physiol. 2004, 29, 447-460. [CrossRef] [PubMed].

[9] Castrogiovanni, P.; Trovato, F. M.; Szychlinska, M. A.; Nsir, H.; Imbesi, R.; Musumeci, G. The importance of physical activity in osteoporosis. From the molecular pathways to the clinical evidence. Histol. Histopathol. 2016, 31, 1183-1194. [PubMed].

[10] Musumeci, G. Sarcopenia and Exercise "The State of the Art". J. Funct. Morphol. Kinesiol. 2017, 2, 40. [CrossRef].

[11] Castrogiovanni, P.; Di Rosa, M.; Ravalli, S.; Castorina, A.; Guglielmino, C.; Imbesi, R.; Vecchio, M.; Drago, F.; Szychlinska, M. A.; Musumeci, G. Moderate Physical Activity as a Prevention Method for Knee Osteoarthritis and the Role of Synoviocytes as Biological Key. Int. J. Mol. Sci. 2019, 20, 511. [CrossRef] [PubMed].

[12] Szychlinska, M. A.; Castrogiovanni, P.; Trovato, F. M.; Nsir, H.; Zarrouk, M.; Lo Furno, D.; Di Rosa, M.; Imbesi, R.; Musumeci, G. Physical activity and Mediterranean diet based on olive tree phenolic compounds from two di erent geographical areas have protective e ects on early osteoarthritis, muscle atrophy and hepatic steatosis. Eur. J. Nutr. 2019, 58, 565-581. [CrossRef] [PubMed].
[13] World Health Organization. Physical activity, https://www.who.int/news-room/fact-sheets/detail/physicalactiv ity (2018, accessed 12 March 2020).

[14] Tiberi M and Piepoli MF. Regular physical activity only associated with low sedentary time increases survival in post myocardial infarction patient. Eur J PrevCardiol 2019; 26: 94 96.

[15] Cheng W, Zhang Z, Cheng W, et al. Associations of leisuretime physical activity with cardiovascular mortality: A systematic review and meta-analysis of 44 prospective cohort studies. Eur J PrevCardiol 2018; 25: 1864-1872.

[16] Engeseth K, Prestgaard EE, Mariampillai JE, et al. Physical fitness is a modifiable predictor of early cardiovascular death: A 35-year follow-up study of 2014 healthy middle-aged men. Eur J PrevCardiol 2018; 25: 1655-1663.

[17] Centers for Disease Control, 2009). Centers for Disease Control and Prevention. (2009). Obesity - Halting the epidemic by making health easier. Atlanta, GA: Centers for Disease Control and Prevention. Retrieved fromhttp://www.cdc.gov/chronicdisease/index.htm.

[18] Cline, K. P., Spradlin, T. E., \&Plucker, J. P. (2005). Child obesity in Indiana: A growing public policy concern. Bloomington, IN: Center for Evaluation \& Education Policy.

[19] Summerbell CD, Waters E, Edmunds L, Kelly SAM, Brown T, \& Campbell KJ. (2005). Interventions for preventing obesity in children. Cochrane Database of Systematic Reviews, Issue 3. Art. No.: CD001871. DOI: 10.1002/14651858.CD001871.pub2.

[20] Harada, T., Okagawa, S., \& Kubota, K. (2004). Jogging improved performance of a behavioralbranching task: implications for prefrontal activation. Neuroscience Research, 49 (3), 325-337. doi: 10.1016/j.neures.2004.03.011.

[21] Sibley, B. A., \& Etnier, J. L. (2003). The relationship between physical activity and cognition inchildren: a meta-analysis. Pediatric Exercise Science, 15, 243-256.

[22] Haskell, W. L., I-Min Lee, F., Pate, R. R., Powell, K. E., Blair, S. N., Franklin, B. A., et al. (2007). Physical activity and public health: Updated recommendation for adults from the American College of Sports Medicine and the American Heart Association. Circulation, 116 (9), 1081-1093.

[23] US Department of Health. (1997). Physical Activity and Health: A Report of the Surgeon General. Atlanta: National Center for Chronic Disease Prevention and Health Promotion. (Biddle \&Mutrie, 2008; Strôhle, 2009).

[24] Biddle, S. J. H., \&Mutrie, N. (2008). Psychology of Physical Activity: Determinants, Wellbeing and Interventions. (2nd ed.). New York: Routledge.

[25] Lawlor \& Hopker, 2001; Lawlor, D. A., \&Hopker, S. W. (2001). The effectiveness of exercise as an intervention in the management of depression: Systematic review and metaregression analysis of randomised controlled trials. British Medical Journal, 322 (7289), 763.

[26] McDonald \& Hodgdon, 1991; McDonald, D. G., \& Hodgdon, J. A. (1991). The Psychological Effects of Aerobic Fitness Training Research and Theory. New York: Springer Verlag. 
[27] North, McCullagh, \& Tran, 1990). North, T. C., McCullagh, P., \& Tran, Z. V. (1990). Effect of exercise on depression. Exercise and Sport Sciences Reviews, 18 (1), 379-416.

[28] Eveland-Sayers, B. M., Farley, R. S., Fuller, D. K., Morgan, D. W., \& Caputo, J. L.(2009). Physical fitness and academic achievement in elementary school children. Journal of Physical Activity and Health, 6, 99-104.

[29] (Augestad, Slettemoen, \& Flanders, 2008; Augestad, L. B., Slettemoen, R. P., \& Flanders, W. D. (2008). Physical activity and depressive symptoms among Norwegian adults aged 20 50. Public Health Nursing, 25 (6), 536-545.

[30] De Moor, Beem, Stubbe, Boomsma, \& De Geus, 2006; De Moor, M. H. M., Beem, A. L., Stubbe, J. H., Boomsma, D. I., \& De Geus, E. J. C. (2006). Regular exercise, anxiety, depression and personality: A population-based study. Preventive Medicine, 42 (4), 273-279. doi: 10.1016/j.ypmed.2005.12.002.

[31] De Moor, Boomsma, Stubbe, Willemsen, \& de Geus, 2008; De Moor, M. H. M., Boomsma, D. I., Stubbe, J. H., Willemsen, G., \& de Geus, E. J. C. (2008). Testing causality in the association between regular exercise and symptoms of anxiety and depression. Archives of General Psychiatry, 65 (8), 897-905.

[32] Goodwin, 2003; Goodwin, R. D. (2003). Association between physical activity and mental disorders among adults in the United States. Preventive Medicine, 36 (6), 698-703. doi: 10.1016/S0091-7435(03)00042-2.

[33] Mutrie \& Hannah, 2007; Mutrie, N., \& Hannah, M. K. (2007). The importance of both setting and intensity of physical activity in relation to non-clinical anxiety and depression. International Journal of Health Promotion and Education, 45 (1), 24-32.

[34] Harvey, Hotopf, Overland, \&Mykletun, 2010; Harvey, S. B., Hotopf, M., Overland, S., \&Mykletun, A. (2010). Physical activity and common mental disorders. The British Journal of Psychiatry, 197 (5), 357-364.

[35] Mikkelsen et al., 2010; Mikkelsen, S. S., Tolstrup, J. S., Flachs, E. M., Mortensen, E. L., Schnohr, P., \&FlensborgMadsen, T. (2010). A cohort study of leisure time physical activity and depression. Preventive Medicine, 51 (6), 471-475. doi: 10.1016/j.ypmed.2010.09.008.

[36] Teychenne, Ball, \& Salmon, 2008; Teychenne, M., Ball, K., \& Salmon, J. (2008). Physical activity and likelihood of depression in adults: A review. [doi: DOI: 10.1016/j.ypmed.2008.01.009]. Preventive Medicine, 46 (5), 397-411.

[37] Thorsen, L., Nystad, W., Stigum, H., Dahl, O., Klepp, O., Bremnes, R. M., et al. (2005). The association between selfreported physical activity and prevalence of depression and anxiety disorder in long-term survivors of testicular cancer and men in a general population sample. Supportive Care in Cancer, 13 (8), 637-646.

[38] Bhaskarabhatla KV and Birrer R. Physical activity and diabetes mellitus. ComprTher 2005; 31: 291-298.

[39] Lippi G and Sanchis-Gomar F. An estimation of the worldwide epidemiologic burden of physical inactivityrelated ischemic heart disease. Cardiovasc Drugs Ther 2020; 34: 133-137.
[40] Brooks SK, Webster RK, S mi th LE, e $t$ al. The $p$ sychological impact of quarantine an $\mathrm{d} h$ ow to re du ce it: $\mathrm{R}$ ap id review of the e vi de nce. Lancet $2020 ; 395$ : 9 12-9 20 .

[41] Silvia Ravalliand Giuseppe Musumeci (2020). Coronavirus Outbreak in Italy: Physiological Benefits of Home-Based Exercise During Pandemic, J. Funct. Morphol. Kinesiol., 5, 31; doi: $10.3390 / \mathrm{jfmk} 5020031$.

[42] Gasmi A, Noor S, Tippairote T, Dadar M. Individual risk management strategy and potential therapeutic options for the COVID-19 pandemic. ClinImmunol. 2020; 7: 108409. DOI: 10.1016/j.clim.2020.108409.

[43] Yuki K, Fujiogi M, Koutsogiannaki S. COVID-19 pathophysiology: A review. ClinImmunol. 2020; 108427. DOI: 10.1016/j.clim.2020.108427.

[44] Scavone C, Brusco S, Bertini M. Current pharmacological treatments for COVID-19: what's next? Br J Pharmacol. 2020. DOI: $10.1111 / \mathrm{bph} .15072$.

[45] Siordia JA Jr. Epidemiology and clinical features of COVID19: A review of current literature. J ClinVirol. 2020; 127: 104357. DOI: $10.1016 /$ j.jcv.2020.104357.

[46] Walsh NP, Gleeson M, Shephard RJ, et al. Position statement. Part one: Immune function and exercise. ExercImmunol Rev. 2011; 17: 6-63. DOI: 10.1002/eji.201040296.

[47] Martin SA, Pence BD, Woods JA. Exercise and respiratory tract viral infections. Exerc Sport Sci Rev. 2009; 37 (4): 15764. DOI: 10.1097/JES.0b013e3181b7b57b.

[48] Lowder T, Padgett DA, Woods JA. Moderate exercise protects mice from death due to influenza virus. Brain Behav Immun. 2005; 19 (5): 377-80. DOI: 10.1016/j.bbi.2005.04.002.

[49] Warren KJ, Olson MM, Thompson NJ. Exercise Improves Host Response to Influenza Viral Infection in Obese and NonObese Mice through Different Mechanisms. PLoS One. 2015; 10 (6): e0129713. DOI: 10.1371/journal.pone.0129713.

[50] Sim YJ, Yu S, Yoon KJ, Loiacono CM. Chronic exercise reduces illness severity, decreases viral load, and results in greater anti-inflammatory effects than acute exercise during influenza infection. J Infect Dis. 2009; 200 (9): 1434-42. DOI: $10.1086 / 606014$.

[51] Davis JM, Kohut ML, Colbert LH. Exercise, alveolar macrophage function, and susceptibility to respiratory infection. J ApplPhysiol (1985). 1997; 83 (5): 1461-6. DOI: 10.1152/jappl.1997.83.5.1461.

[52] Murphy EA, Davis JM, Carmichael MD. Exercise stress increases susceptibility to influenza infection. Brain Behav Immun. 2008; 22 (8): 1152-5. DOI: 10.1016/j.bbi.2008.06.004.

[53] Lowder T, Padgett DA, Woods JA. Moderate exercise early after influenza virus infection reduces the Th1 inflammatory response in lungs of mice. ExercImmunol Rev. 2006; 12: 97111. DOI: 10.1016/j.bbi.2005.04.002.

[54] Murphy EA, Davis JM, Brown AS, Carmichael MD, Van Rooijen N, Ghaffar A, Mayer EP. Role of lung macrophages on susceptibility to respiratory infection following short-term moderate exercise training. Am J PhysiolRegulIntegr Comp $\begin{array}{llll}\text { Physiol. 2004; } 287 \quad \text { (6): } & \text { R1354-8. DOI: }\end{array}$ 10.1016/j.bbi.2008.06.004. 
[55] Kohut ML, Davis JM, Jackson DA, Colbert LH, Strasner A, Essig DA, Pate RR, Ghaffar A, Mayer EP. The role of stress hormones in exercise-induced suppression of alveolar macrophage antiviral function. J Neuroimmunol. 1998; 81 (12): 193-200. DOI: 10.1016/s01655728(97)00179-3.

[56] Kohut ML, Martin AE, Senchina DS, Lee W. Glucocorticoids produced during exercise may be necessary for optimal virusinduced IL-2 and cell proliferation whereas both catecholamines and glucocorticoids may be required for adequate immune defense to viral infection. Brain Behav Immun. 2005; 19 (5): 423-35. DOI: 10.1016/j.bbi.2005.04.006

[57] Nieman DC, Johanssen LM, Lee JW, Arabatzis K. Infectious episodes in runners before and after the Los Angeles Marathon. J Sports Med Phys Fitness. 1990; 30 (3): 316-28. DOI: 10.1249/00005768-199402000-00002.

[58] Nieman DC. Exercise, upper respiratory tract infection, and the immune system. Med Sci Sports Exerc. 1994; 26 (2): 12839. DOI: 10.1249/00005768-199402000-00002.

[59] Svendsen IS, Hem E, Gleeson M. Effect of acute exercise and hypoxia on markers of systemic and mucosal immunity. Eur $J$ Appl Physiol. 2016; 116 (6): 1219-29. DOI: 10.1007/s00421016-3380-4.

[60] Gleeson M, Bishop N, Oliveira M, McCauley T, Tauler P, Muhamad AS. Respiratory infection risk in athletes: association with antigen-stimulated IL-10 production and salivary IgA secretion. Scand J Med Sci Sports. 2012; 22 (3): 410-7. DOI: $10.1111 /$ j.1600-0838.2010.01272.x.

[61] Rooney BV, Bigley AB, LaVoy EC et al. Lymphocytes and monocytes egress peripheral blood within minutes after cessation of steady state exercise: A detailed temporal analysis of leukocyte extravasation. Physiol Behav. 2018; 194: 260267. DOI: 10.1016/j.physbeh.2018.06.008.

[62] Simpson RJ, Campbell JP, Gleeson M, et al. Can exercise affect immune function to increase susceptibility to infection? ExercImmunol Rev. 2020; 26: 8-22.

[63] Weidner TG, Cranston T, Schurr T, et al. The effect of exercise training on the severity and duration of a viral upper respiratory illness. Med Sci Sports Exerc. 1998; 30 (11): 157883. DOI: 10.1097/00005768-199811000-00004.

[64] Vassilakopoulos T, Petrof BJ. Ventilator-induced diaphragmatic dysfunction. Am J Respir Crit Care Med.2004; 169 (3): 336-341. DOI: $10.1164 / \mathrm{rccm} .200304-489 \mathrm{CP}$

[65] McKenzie DC. Respiratory physiology: adaptations to highlevel exercise. Br J Sports Med. 2012; 46 (6): 381-384. DOI: 10.1136/bjsports-2011-090824.

[66] Powers SK, Bomkamp M, Ozdemir M, et al. Mechanisms of exercise-induced preconditioning in skeletal muscles. Redox Biol. 2020; 101462. DOI: 10.1016/j.redox.2020.101462.

[67] Morton AB, Smuder AJ, Wiggs MP, et al. Increased SOD2 in the diaphragm contributes to exercise-induced protection against ventilator-induced diaphragm dysfunction. Redox Biol. 2019; 20: 402-413. DOI: 10.1016/j.redox.2018.10.005.

[68] Smuder AJ, Min K, Hudson MB, et al. Endurance exercise attenuates ventilator-induced diaphragm dysfunction. $J$ Appl $\begin{array}{lllll}\text { Physiol. } & \text { 2012; } & 112 & \text { (3): } & \text { 501-510. }\end{array}$ 10.1152/japplphysiol.01086.2011.

[69] Smuder AJ, Morton AB, Hall, S E, et al. Effects of exercise preconditioning and HSP72 on diaphragm muscle function during mechanical ventilation. J Cachexia Sarcopenia Muscle. 2019; 10 (4): 767-781. DOI: 10.1002/jcsm.12427.

[70] Bowden Davies KA, Pickles S, Sprung VS, Kemp GJ, Alam U, Moore DR, Tahrani AA \& Cuthbertson DJ. Reduced physical activity in young and older adults: metabolic and musculoskeletal implications. Ther Adv Endocrinol Metab. 2019; 10 : $2042018819888824 . \quad$ DOI: $10.1177 / 2042018819888824$.

[71] Piercy KL, Troiano RP, Ballard RM, et al. The physical activity guidelines for Americans. JAMA. 2018; 32019: 20202028. DOI: 10.1001/jama.2018.14854.

[72] Anderson E, Durstine JL. Physical activity, exercise, and chronic diseases: a brief review. Sports Med Health Sci. 2019; 1 (1): 3-10. DOI: 10.1016/j.smhs.2019.08.006.

[73] World Health Organization. Global Strategy on Diet, Physical Activity and Health. 2011 a; https://www.who.int/dietphysicalactivity/factsheet_adults/en/.

[74] World Health Organization. Global Strategy on Diet, Physical Activity and Health. 2011b; dations-5-17years.pdf?ua=1" https://www.who.int/dietphysicalactivity/publications/physical -activity-recommendations-517years.pdf?ua=1.

[75] Norton S, Matthews FE, Barnes DE, et al. Potential for primary prevention of Alzheimer's disease: an analysis of population-based data. Lancet Neurol.2014; 13: 788-794. DOI: 10.1016/S1474-4422(14)70136-X.

[76] Liguori G. ACSM's Guidelines for Exercise Testing and Prescription. 11th ed. Philadelphia, PA: Wolters Kluwer; 2017.

[77] World Health Organization. (2010). Global recommen-dations on physical activity for health.

[78] Bangsbo, J., Mohr, M., Poulsen, A., Perez-Gomez, J., \&Krustrup, P. (2006). Training and testing the elite athlete. Review. Journal of Exercise Science and Fitness, 4 (1), 1-14.

[79] Fox et al., 1971; Fox, S. M. 3rd., Naughton, J. P., \& Haskell, W. L. (1971). Physical activity and the prevention of coronary heart disease. Annals of Clinical Research, 3 (6), 404-432. PMID: 4945367.

[80] Garber, C. E., Blissmer, B., Deschenes, M. R., Franklin, B. A., Lamonte, M. J., Lee, I.-M., Nieman, D. C., \& Swain, D. P. (2011). Quantity and quality of exercise for developing and maintaining cardiorespiratory, musculoskeletal, and neuromotor fitness in appar-ently healthy adults: Guidance for prescribing exer-cise SPECIAL COMMUNICATIONS: POSITION STAND. Medicine \& Science in Sports \& Exercise, 43 (7), 1334-1359. https://doi.org/10.1249/MSS.0b013e318213fefb.

[81] Barene, S., Krustrup, P., Jackman, S. R., Brekke, O. L., \&Holtermann, A. (2014). Do soccer and Zumba exer-cise improve fitness and indicators of health among female hospital employees? A 12-week RCT. Scandinavian Journal of Medicine \& Science in Sports, 24 (6), 990-999. https://doi.org/10.1111/ sms.12138.

[82] Connolly, L. J., Scott, S., Morencos, C. M., Fulford, J., Jones, A. M., Knapp, K., Krustrup, P., Bailey, S. J., \& Bowtell, J. L. (2020). Impact of a novel home-based exercise intervention on health indicators in inactive premenopausal women: A 12week randomised controlled trial. European Journal of Applied Physiology, Mar 19. [Epub ahead of print]. https://doi.org/10.1007/s00421-020- 04315-7. 
[83] Alpert, P. T. (2011). The health benefits of dance. Home Health Care Management \& Practice, 23 (2), 155-157. https://doi.org/10.1177/1084822310384689.

[84] Hernandes, J. C., Di Castro, V. C., Mendonça, M. E., \& Porto, C. C. (2018). Quality of life of women who practice dance: A systematic review protocol. Systematic Reviews, 7 (1), 92. https://doi.org/10.1186/s13643-018-0750-5\.

[85] Connolly, L. J., Bailey, S. J., Krustrup, P., Fulford, J., Smietanka, C., \& Jones, A. M. (2017). Effects of self-paced interval and continuous training on health markers in women. European Journal of Applied Physiology, 117 (11), 22812293. https://doi.org/10.1007/s00421-017-3715-9.

[86] AmriHammami, BasmaHarrabi, Magni Mohr \& Peter Krustrup (2020): Physicalactivity and coronavirus disease 2019 (COVID-19): specific recommendations for home-based physical training, Managing Sport and Leisure, 10. DOI: 1080/23750472.2020.1757494.

[87] Tanaka, H., Monahan, K. D., \& Seals, D. R. (2001). Agepredicted maximal heart rate revisited. Journal of the American College of Cardiology, 37 (1), 153-156. https://doi.org/10.1016/S0735-1097(00)01054-.
[88] Harrison, J. S. (2010). Bodyweight training: A return to basics Strength and Conditioning Journal, 32 (2), 52-55. https://doi.org/10.1519/SSC.0b013e3181d 5575c.

[89] Jönhagen, S., Ackermann, P., \& Saartok, T. (2009). Forward lunge: A training study of eccentric exer-cises of the lower limbs. Journal of Strength and Conditioning Research, 23 (3), 972-978. https://doi.org/10.1519/JSC.0b013e3181a00d98.

[90] Kikuchi, N., \&Nakazato, K. (2017). Low-load bench press and push-up induce similar muscle hypertro-phy and strength gain. Journal of Exercise Science \& Fitness, 15 (1), 37-42. https://doi.org/10.1016/j.jesf. 2017.06.003.

[91] Watanabe, Y., Tanimoto, M., Oba, N., Sanada, K., Miyachi, M., \& Ishii, N. (2015). Effect of resistance training using bodyweight in the elderly: Comparison of resistance exercise movement between slow and normal speed movement. Geriatrics Gerontology International, 15 (12), 1270- 1277. https://doi.org/10.1111/ggi.12427.

[92] Lipecki, K., \&Rutowicz, B. (2015). The impact of ten weeks of bodyweight training on the level of phys-ical fitness and selected parameters of body com-position in women aged 2123 years. Polish Journal of Sport and Tourism, 22 (2), 64-68. https://doi.org/10.1515/pjst-2015-0014. 